\title{
Modeling heat transfer in down flowing annular weakly turbulent vapor-liquid flows during evaporation
}

\author{
Valentyn Petrenko, Mykola Priadko, Oleksandr Riabchuk
}

\author{
National University of Food Technologies, Kyiv, Ukraine
}

Keywords:

Heat transfer

Film

Turbulent

viscosity

Velocity

Evaporation

Article history:

Received

16.03.2020

Received in revised

form 29.08.2020

Accepted

27.12.2020

\section{Corresponding \\ author:}

Valentyn Petrenko

E-mail:

Petrenkovp@ukr.net

DOI:

$10.24263 / 2304-$

974X-2020-9-4-14

\section{Abstract}

Introduction. The predominant number of relations for turbulent viscosity in down flowing films has a discrete layered structure, and the solutions of the heat and momentum conservation equations using these relations are only numerical. A new model is proposed and on its basis the analysis of thermohydrodynamic processes in films of liquids during vaporization is carried out

Materials and methods. Physical modeling was performed in pipes: $d=22 \times 1 \mathrm{~mm}, L=1,8 \mathrm{~m}$, and $d=33 \times 1,5 \mathrm{~mm}, L=9 \mathrm{~m}$. The bulk density of irrigation varied in the range of $0,05-0,55 \cdot 10^{-3} \mathrm{~m}^{2} / \mathrm{s}$ in the pipe $d=20 \mathrm{~mm}$, and $0,05-1,9 \cdot 10^{-3} \mathrm{~m}^{2} / \mathrm{s}$ in the pipe $d=30 \mathrm{~mm}$. Model liquids - water and sugar solutions with a concentration of up to $70 \%$ at atmospheric pressure and a vacuum of up to $0,86 \mathrm{bar}$. Heating was carried out with dry saturated steam.

Results and discussion. A model of turbulent viscosity in a film in the form of a beveled interfacial surface of a parabola is proposed. Analytical expressions for temperature and velocity profiles in the film and corresponding integral thermohydrodynamic characteristics for the heat transfer regime characterized by evaporation from the interfacial surface are obtained from the heat transfer and momentum conservation equations.

Analytical expressions for heat transfer coefficient and film thickness are expressed in inverse hyperbolic functions and are simply correlated with the corresponding experimental data on heat transfer in flowing films of water and thick sugar solutions in the area of undeveloped and developed turbulence during vaporization. Experimental data on heat transfer in the presence of interfacial tangential stress on the film surface correlate with the theoretical results of the proposed model only with the introduction of an additional function that takes into account the suppression of turbulence in the film due to its thinning, expressed in Weber numbers for the vapor phase. According to experimental data, the effect of bubble boiling on the intensity of heat transfer during the movement of the vapor-liquid core is manifested only outside the limiting temperature pressure, expressed by the Clapeyron-Clausius ratio, and is taken into account by introducing the parameter turbulent viscosity models.

Conclusions. Based on the proposed model of turbulent viscosity, the analysis of thermohydrodynamic processes of weakly turbulent film flows is performed, the corresponding analytical expressions for calculation of heat transfer to films of solutions during vaporization in pipes, including bubble boiling region are obtained. 


\section{Introduction}

Boiling fruit juices and sugar solutions in down flowing films in long evaporation channels under vacuum allows to obtain high-quality food concentrates, so this direction is developing, and film evaporators are improving.

The processes of heat and momentum transfer in flowing films of liquid differ significantly from the processes of transfer in a continuous medium due to the presence of an elastic, due to surface tension, interfacial surface covered with a system of waves. Measurements of turbulent viscosity in films given in the works of D.C. Jepsen and B.G. Ganchev, indicate its rapid fall near the interfacial surface, and the shape of the turbulence curve is deformed depending on the orientation of the film relative to the direction of gravity. Thus, in films flowing on inclined (at an angle of $9^{\circ}$ ) surfaces in the region of Reynolds numbers up to 1800 turbulent viscosity has an almost parabolic profile, Figure 1.A., while in the films flowing down the vertical surface, there is a deformation of the parabola with a flat part near the wall and a rapid fall near the interfacial surface, Figure 1. B.

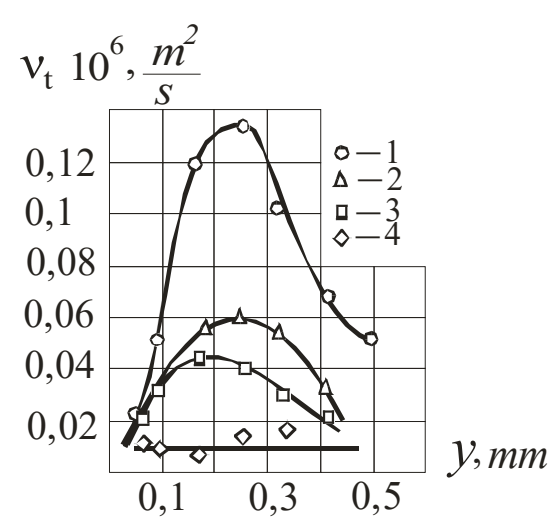

$\mathbf{A}$

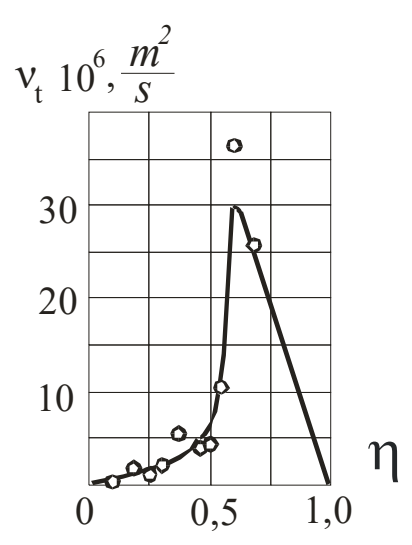

B

Figure 1. The dependence of turbulent viscosity on the film thickness of water $\left(t=20^{\circ} \mathrm{C}\right)$. $A$ - flow along an inclined angle of $9^{\circ}$ (D.C. Jepsen); 1 - $R e=1834 ; 2-1462 ; 3-1099 ; 4-732$, (method of $\mathrm{CO}_{2}$ absorption);

B - flow along the vertical surface (B.G. Ganchev) $R e=1310$, (method of stroboscoping of alumina microparticles).

In single-phase continuous media, modeling of complex near-wall flows is carried out mainly by direct numerical modeling based on grid methods, or modeling based on ANSYS software using either differential and turbulence models $[1,2,3,4]$, or mixed - in the nearwall algebraic form, and in the external - differential. Works on the application $k-\varepsilon$ and $k-\omega$ models for the reproduction of thermohydrodynamic characteristics of film flows with a wave structure have not been found in the literature. In addition, as a result of the application of differential models, only numerical solutions of the differential equations of motion and heat exchange are obtained, while artificial algebraic models $[5,6,7,8,9]$, which with a certain approximation copy the shape of the turbulent viscosity distribution curve in films, 
having a relatively simple form, give satisfactory analytical results on the reproduction of thermohydrodynamic processes in films flowing on vertical surfaces.

A successful algebraic relation for turbulent viscosity in films is the expression of M.D. Millionshchikov, which postulates the presence of a laminar layer thickness $\delta_{l}^{+}=7,8$, and a turbulent nucleus in the region $\frac{7,8}{\delta^{+}} \leq \eta \leq 1$ with a parabolic profile $v_{t} / v$.

$$
\frac{v_{t}}{v}=0,39\left(\eta \delta^{+}-\delta_{r}^{+}\right)(1-\eta),
$$

where $y$-normal to the heat surface coordinate; $\delta$-film thickness; $\eta=\frac{y}{\delta}$-dimensionless transverse coordinates; $v_{t}, v$ - turbulent and molecular cinematic viscosity coefficient, respectively; $\rho$-density of liquid; $\tau_{i}$ - shear stress on the film interface; $g$-acceleration of gravity; $\eta_{n}=\frac{\delta_{r}}{\delta}=\frac{\delta_{l}^{+}}{\delta^{+}} ; \delta_{r}^{+}=\frac{\delta_{n} u^{*}}{v}=7,8 ; \delta^{+}=\frac{\delta u^{*}}{v} ; u^{*}=\sqrt{\frac{\tau_{i}+\rho g \delta}{\rho}} ; \delta_{r}=\frac{7,8 v}{u^{*}}$.

In the case of replacing the constant coefficient $(0,39)$ by a function of the flow and mode parameters of the film, expression (1) becomes convenient for analysis and generalization of experimental results on heat transfer and hydrodynamics of film flows. At the same time, the abrupt increase in turbulent viscosity at the outer boundary of the laminar layer in expression (1) seems physically unreasonable. In addition, the model (1) has a layered change in viscosity, so when solving the heat transfer equations there is a need to join the solutions between the laminar and turbulent layers. Two-layer algebraic models of turbulence in films with ascending and descending branches of the turbulent viscosity function have become widespread $[5,6,7,8,9]$. At the same time, in the near-wall and interfacial regions a gradual continuous transition from the laminar to the turbulent mode of motion is postulated. But the profiles proposed in $[5,6,7,8,9]$, in contrast to (1), do not allow to obtain solutions of the equations of motion and thermal conductivity in quadratures. The continuous distribution function of turbulent viscosity over the entire thickness of the free-flowing film with a gradual, in the form of Van Drist correction, transition from laminar to turbulent mode in the near-wall region and within the interfacial surface of the film was proposed by Mudawwar [10]. Later, this model of turbulence was developed for flows with concomitant steam flow over the surface of the film [11].

$$
\frac{v_{t}}{v}=-\frac{1}{2}+\frac{1}{2}\left(1+l^{+2} \frac{\tau_{i}+\rho g(\delta-y)}{\tau_{i}+\rho g \delta}\right)^{0,5},
$$

where $y^{+}=\frac{y u^{*}}{v} ; l^{+}=0,4 y^{+}\left[1-\exp \left(-\frac{y^{+}}{26}\right)\right]\left\{1-\exp \left[n\left(\frac{y^{+}}{\delta^{+}}-1\right)\right]\right\}$; $n=19,435 \operatorname{Re}^{-0,345} \operatorname{Pr}^{-0,34}\left(1+\tau_{i}^{*}\right)^{0,163} ; \operatorname{Re}=\frac{4 G_{v}}{v}-$ the Reynolds number; $\operatorname{Pr}-$ the Prandtl 
number; $G_{v}=\frac{G}{\rho \pi d}-$ volumetric liquid flux; $G-$ mass flow rate; $\tau_{i}^{\cdot}=\frac{\tau_{i}}{\rho g\left(\frac{v^{2}}{g}\right)^{1 / 3}}-$

dimensionless shear stress on the film interface; $d$-pipe diameter.

Graphically, the dependences $(1,2)$ are shown in Figure 2.

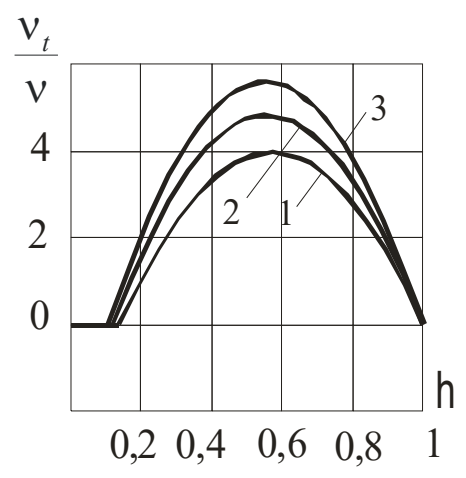

A

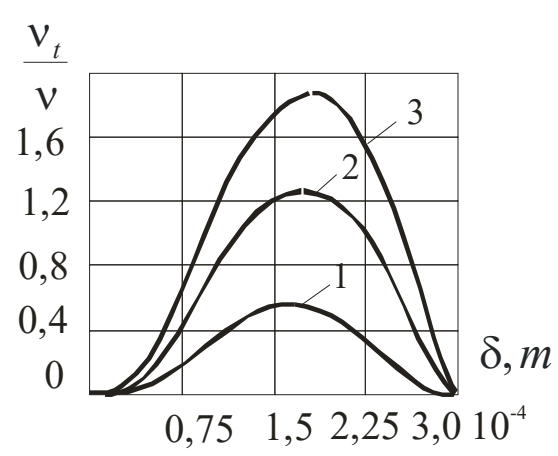

B

Figure 2. Distribution of turbulent viscosity in the cross section of the film by relations (1) and (2).

$$
\begin{gathered}
G_{v}=0,3 \cdot 10^{-3} \frac{m^{2}}{s} ; 1-\tau_{i}=0 \frac{N}{m}, 2-1 ; 2-2 . \\
\mathrm{A}-(1), \mathrm{B}-(2) .
\end{gathered}
$$

Under the conditions of interfacial shear stress, according to (2), there is a shift of the maximum of the turbulence function from the middle of the film to the interfacial surface with its simultaneous growth, which corresponds to the physical idea of the turbulence process in the film, but obviously only to a certain extent. since with increasing interfacial tangential voltage, the film thickness, as well as the scale of turbulence, decrease.

Given the imperfections of existing models, the algebraic model of turbulence seems to be effective, which, firstly, with some approximation will reproduce the real distribution of turbulent viscosity in the film, and secondly, will perform analytical solutions of transfer equations for film flows.

Purpose of the study - on the basis of the proposed new algebraic model of turbulent viscosity to perform the analysis of thermohydrodynamic processes in the descending annular flows of liquids and solutions during vaporization.

\section{Materials and methods}

The object of research - film flows of saturated weakly turbulent liquids with concomitant steam flow.

\section{Research methods}


Physical modeling of heat transfer processes was performed in a stainless steel pipe with a diameter of $22 \times 1 \mathrm{~mm}$ and a length of $1,8 \mathrm{~m}$, divided into a stabilization section with a length of $1,5 \mathrm{~m}$ and a measurement section. Heating was carried out with dry saturated steam, the boiling of the film was simulated in the range of absolute pressures $10^{5}-1,410^{4}$ $\mathrm{Pa}$. The volumetric liquid flux varied in the range of $0,05-0,55 \times 10^{-3} \mathrm{~m}^{2} / \mathrm{s}$. The model liquids were water and sugar solutions with a concentration of $20-70 \%$. Temperatures were measured with copper-constantan thermocouples. In addition, we used experimental data obtained on a model installation of a stainless steel heat exchange tube with a length of $9 \mathrm{~m}$ and an inner diameter of $30 \mathrm{~mm}$, partitioned into 20 sections with a length of $440 \mathrm{~mm}$ with drainage of each formed condensate into separate adiabatic measuring cups, and data [12], obtained on an installation with a pipe length of $3,9 \mathrm{~m}$ and a diameter of $32 \mathrm{~mm}$ to simulate the process of concentrating apple juice under vacuum. The volumetric liquid flux in a pipe with a diameter of $30 \mathrm{~mm}$ varied in the range of $0,05-1,9 \times 10^{-3} \mathrm{~m}^{2} / \mathrm{s}$.

The simulation of the down flowing annular two-phase steams-liquid flow with the shear stress on the film interface was carried out by the method of forced independent introduction of steam in the upper part of the stabilization section of the experimental channel. The introduction of liquid into the pipe is performed by the method of transfusion through the edge, which corresponds to the real conditions of film formation in the pipes of film evaporators. Measurement of heat flux was performed by the method of collecting condensate from the model area in adiabatic measuring cups. Thermocouples were connected to the I-7018P analog input modules, which were connected to one I-7520 module with computer output for data storage. Survey of thermocouples during experiments $0.1-2 \mathrm{~s}$.

\section{Results and discussion}

It is known that when the film of liquid flows down the vertical surface, even at low irrigation density, a wave structure is formed on its surface. At a distance of 2-2,5 $\mathrm{m}$ from the film-forming device comes the mode of saturation of wave motion [14] with the formed structure of low-frequency large waves, which "roll" on the interfacial surface covered with high-frequency waves. The movement of large waves on the surface of the film is accompanied by mixing of the liquid, and, accordingly, the deformation of velocity, temperature and concentration. Analysis of heat transfer processes in films with a developed wave structure based on the model of cyclic perturbation of the film by large waves was performed in [13], but the obtained results are difficult for engineering calculations. Therefore, a simplified heat transfer model based on the averaged thermohydrodynamic parameters of the film flow and the average turbulence parameters for the quasi-stationary film flow regime is considered. The film is considered conditionally flat, and surface waves act as turbulizers.

\section{Modeling of heat transfer in free-flowing weakly turbulent evaporating films}

To model the turbulence and, accordingly, the transfer processes in a vertically flowing film, consider the expression

$$
\frac{v_{t}}{v}=\varepsilon \eta^{2}\left(1-\eta^{2}\right)
$$


where $\varepsilon$-the maximum value of the function at the vertex of the deformed parabola.

The graph of dependence (3) is shown in Figure 3.

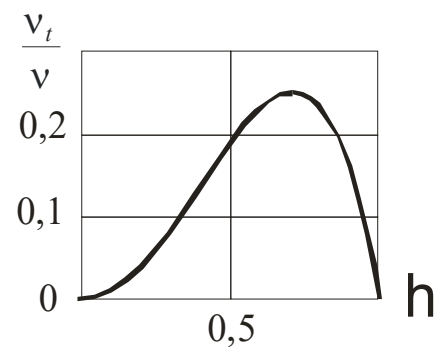

Figure 3. Graph of dependence (3) at $\varepsilon=1$.

The shape of the curve in Figure 3 seems to be the most adequate to the real distribution of turbulent viscosity in films in vertical channels with free flow, (Figure $1 \mathrm{~b}$.). The maximum value of function (3) at the vertex of the deformed parabola depends on the flow parameters of the film, the degree of development of the wave structure, etc., and can be determined by comparing the calculated and experimental values of thermohydrodynamic parameters of the film flow.

Given the simplifications regarding the mode of motion of the film, the heat transfer process can be provided as

$$
q=-\left(\frac{\lambda}{\delta}\right)\left(1+\frac{\operatorname{Pr}}{\operatorname{Pr}_{t}} \frac{v_{t}}{v}\right) \frac{d t}{d \eta}
$$

where $q$-heat flow; $\lambda$-heat conduction of liquid; $t$-temperature; $\operatorname{Pr}_{t}$-turbulent Prandtl number.

Accepting $\operatorname{Pr}_{t}=1$, taking into account (3) under boundary conditions $\eta=0, t=t_{w}$, we obtain the temperature profile in the film

$$
t=t_{w}-\frac{q \delta}{\lambda} \frac{\sqrt{2} H}{(4+\varepsilon \operatorname{Pr})}\left[\frac{1}{R} \operatorname{Arth}\left(\frac{\sqrt{2} \varepsilon \operatorname{Pr}}{R} \eta\right)-\frac{1}{A} \operatorname{Arth}\left(\frac{\sqrt{2} \varepsilon \operatorname{Pr}}{A} \eta\right)\right],
$$

where $H=\sqrt{4 \varepsilon \operatorname{Pr}+\varepsilon^{2} \operatorname{Pr}^{2}} ; \quad A=\sqrt{\varepsilon^{2} \operatorname{Pr}^{2}-\varepsilon \operatorname{Pr} H} ; \quad R=\sqrt{\varepsilon^{2} \operatorname{Pr}^{2}+\varepsilon \operatorname{Pr} H}$.

From equation (5) provided $\eta=1, t=t_{i}$ the temperature on the interfacial surface

$$
t_{i}=t_{w}-\frac{q \delta}{\lambda} \frac{\sqrt{2} H}{(4+\varepsilon \operatorname{Pr})}\left[\frac{1}{R} \operatorname{Arth}\left(\frac{\sqrt{2} \varepsilon \operatorname{Pr}}{R}\right)-\frac{1}{A} \operatorname{Arth}\left(\frac{\sqrt{2} \varepsilon \operatorname{Pr}}{A}\right)\right]
$$

where, $t_{w}, t_{i}$-wall temperature and liquid film saturation temperature on the interface, respectively.

Expressing the heat transfer coefficient as $\alpha=\frac{q}{t_{w}-t_{i}}$, with (6) we obtain 


$$
\alpha=\frac{\lambda}{\delta} \frac{(4+\varepsilon \operatorname{Pr})}{\sqrt{2} H N},
$$

where $N=\left[\frac{1}{R} \operatorname{Arth}\left(\frac{\sqrt{2} \varepsilon \operatorname{Pr}}{R}\right)-\frac{1}{A} \operatorname{Arth}\left(\frac{\sqrt{2} \varepsilon \operatorname{Pr}}{A}\right)\right]$.

In expression (7) there is a film thickness, which is determined from the equation of motion using function (3)

$$
\frac{\tau_{i} \delta}{\rho v}+\frac{g \delta^{2}}{v}(1-\eta)=\left[1+\varepsilon\left(\eta^{2}-\eta^{4}\right)\right] \frac{d u}{d \eta},
$$

where $u$-velocity.

From (8) under boundary conditions $\eta=0, u=0$, we obtain the velocity profile

$$
\begin{aligned}
& u=\left(\frac{\tau_{i} \delta}{\rho v}+\frac{g \delta^{2}}{v}\right) \frac{\sqrt{2} h}{(4+\varepsilon)}\left[\frac{1}{r} \operatorname{Arth}\left(\frac{\sqrt{2} \varepsilon}{r} \eta\right)-\frac{1}{a} \operatorname{Arth}\left(\frac{\sqrt{2} \varepsilon}{a} \eta\right)\right]- \\
& -\frac{g \delta^{2}}{v h}\left[\operatorname{Arth}\left(\frac{\varepsilon\left(2 \eta^{2}-1\right)}{h}\right)+\operatorname{Arth}\left(\frac{\varepsilon}{h}\right)\right],
\end{aligned}
$$

where $h=\sqrt{4 \varepsilon+\varepsilon^{2}} ; \quad a=\sqrt{\varepsilon^{2}-\varepsilon h} ; \quad r=\sqrt{\varepsilon^{2}+\varepsilon h}$;

$$
n=\left[\frac{1}{r} \operatorname{Arth}\left(\frac{\sqrt{2} \varepsilon}{r}\right)-\frac{1}{a} \operatorname{Arth}\left(\frac{\sqrt{2} \varepsilon}{a}\right)\right] \text {. }
$$

The average speed $\quad \bar{u}=\int_{0}^{1} u d \eta$ is obtained from (9)

$$
\begin{aligned}
& \bar{u}=\left(\frac{\tau_{i} \delta}{\rho v}+\frac{g \delta^{2}}{v}\right) \frac{\sqrt{2} h}{(4+\varepsilon)}\left[n-\frac{\sqrt{2}}{4 \varepsilon} \ln \left(\frac{a^{2}-2 \varepsilon^{2}}{r^{2}-2 \varepsilon^{2}}\right)-\frac{\sqrt{2}}{2 \varepsilon} \ln \left(\frac{r}{a}\right)\right]- \\
& -\frac{g \delta^{2}}{v h}\left[2 \operatorname{Arth}\left(\frac{\varepsilon}{h}\right)-\frac{\sqrt{2} h}{2}\left(\frac{1}{r} \operatorname{Arth}\left(\frac{\sqrt{2} \varepsilon}{r}\right)+\frac{1}{a} \operatorname{Arth}\left(\frac{\sqrt{2} \varepsilon}{a}\right)\right)-\frac{\sqrt{2} \varepsilon}{2} n\right]
\end{aligned}
$$

Given that the film thickness $\delta$ and the average velocity $\bar{u}$ are related to the volumetric liquid flux $G_{v}$ dependence $\delta=\frac{G_{v}}{\bar{u}}$, we obtain the expression for the average film thickness in the form of a cubic equation

$$
G_{v}=\left(\frac{\tau_{i} \delta^{2}}{\rho v}\right) D+\frac{g \delta^{3}}{v h}(D h-B),
$$


where

$$
\begin{aligned}
& B=\left[2 \operatorname{Arth}\left(\frac{\varepsilon}{h}\right)-\frac{\sqrt{2} h}{2}\left(\frac{1}{r} \operatorname{Arth}\left(\frac{\sqrt{2} \varepsilon}{r}\right)+\frac{1}{a} \operatorname{Arth}\left(\frac{\sqrt{2} \varepsilon}{a}\right)\right)-\frac{\sqrt{2} \varepsilon}{2} n\right], \\
& D=\frac{\sqrt{2} h}{(4+\varepsilon)}\left[n-\frac{\sqrt{2}}{4 \varepsilon} \ln \left(\frac{a^{2}-2 \varepsilon^{2}}{r^{2}-2 \varepsilon^{2}}\right)-\frac{\sqrt{2}}{2 \varepsilon} \ln \left(\frac{r}{a}\right)\right] .
\end{aligned}
$$

In the case of free flow ( $\left.\tau_{i}=0\right)$, the film thickness is directly from (11)

$$
\delta=\sqrt[3]{\frac{G_{v} v h}{g(D h-B)}},
$$

and the expression for the heat transfer coefficient for free flow conditions is written as

$$
\alpha=\frac{\lambda}{\sqrt[3]{\frac{G_{v} v h}{g(D h-B)}}} \frac{(4+\varepsilon \operatorname{Pr})}{\sqrt{2} H N} .
$$

In expression (13) for the condition of free flow, the only unknown parameter is the function of the maximum turbulent viscosity at the vertex of the parabola in expression (3) $\varepsilon$, which is essentially a correlation parameter. The function is found by comparing the experimental and calculated (13) values of the heat transfer intensity to the film in the mode of evaporation from the interfacial surface. For water and sugar solutions during vaporization in a pipe with a diameter of $20 \mathrm{~mm}$ (Figure 4) the relation for the function $\varepsilon$ in (3) is obtained in the form, (Figure 4)

$$
\varepsilon=5 \cdot 10^{-5} \mathrm{Re}^{1,4}
$$

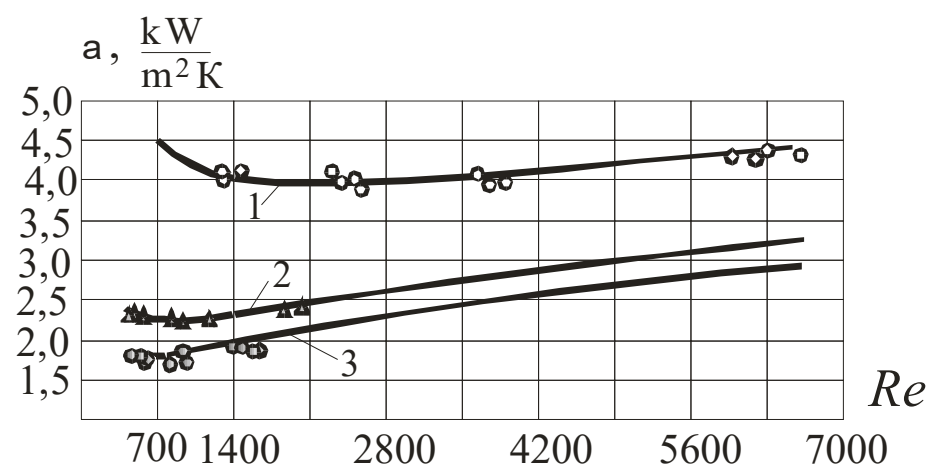

Figure 4. Dependence $\alpha=f(\mathrm{Re})$ for water and sugar solutions in a pipe with a diameter of $20 \mathrm{~mm}$, length $L=1,5 \mathrm{~m}, t=100{ }^{\circ} \mathrm{C}$.

1 - water; 2,3 - sugar solutions. 2 - DM= 40\%; $3-50 \%$. 
Since wave formation at the same volumetric liquid flux develops differently in channels of different diameters, then, accordingly, the turbulence in the film should depend on the geometry of the channel. The effect of surface curvature on heat transfer in the form (13) can be estimated by comparing experimental data on heat transfer to films in pipes of different diameters with the results of calculation by $(13,14)$. The result is a function of dependence $\varepsilon$ on the diameter of the pipe in the form of a factor to (14), which has the form of an exponential function

$$
\varepsilon=5 \cdot 10^{-5} \operatorname{Re}^{1,4}\left\{1+3,6\left[1-\exp \left(1-\frac{d}{d_{o}}\right)\right]\right\},
$$

where $d_{o}=0,02 \mathrm{~m}$.

Graphical interpretation of the results of calculations by $(13,15)$ for free-flowing films of water in the mode of evaporation from the interfacial surface in pipes of different diameters and comparison with experimental data is shown in Figure5.

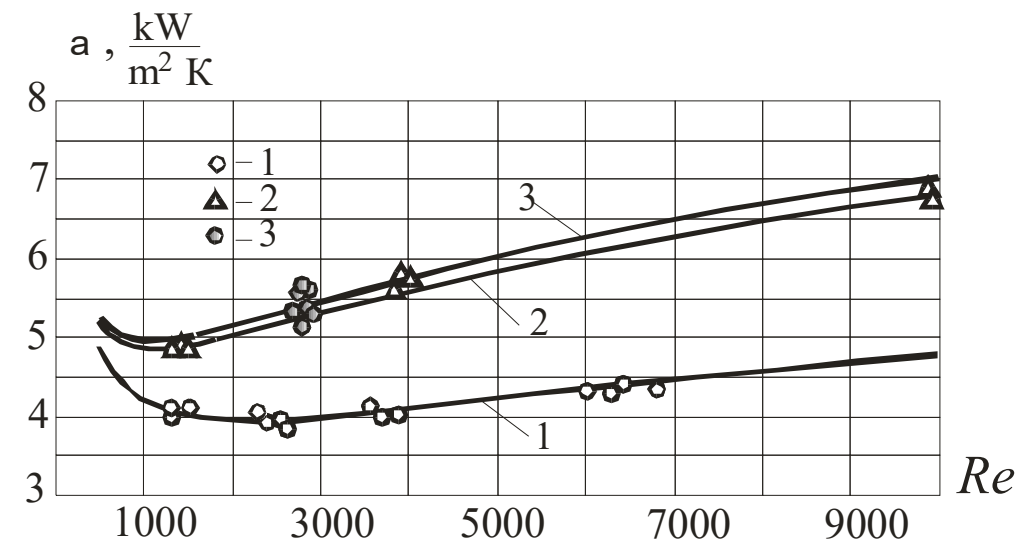

Figure 5. Dependence $\alpha=f(\mathrm{Re})$ for pipes of different diameters.

1 - data of the authors, $d=20 \mathrm{~mm} ; 2-d=30 \mathrm{~mm} ; 3-$ data [12], $d=32 \mathrm{~mm}$, water $t=100{ }^{\circ} \mathrm{C}$.

\section{Simulation of heat transfer in flowing weakly turbulent films in the presence of interfacial the shear stress}

In the presence of the vapor velocity above the surface of the film and, accordingly, the shear stress on the film interface, the film thickness decreases, and the parameters of the wave structure of the film change. Thus, according to [14], the flow of gas over the surface of the vertically flowing film leads to a decrease in the amplitude of the waves and an increase in their frequency. These factors also affect the parameters of turbulence. In the absence of direct measurements of the turbulence intensity profile in the films during the movement of the gas flow (vapor) over its surface, it is convenient to make an assumption that only the parameter changes, while the shape of the turbulent viscosity profile curve (3) is slightly 
deformed. The new value of the turbulence function at the vertex of the parabola shifted relative to the middle of the film $\varepsilon$ is given in the form of the product (13) with the function of turbulence suppression by steam flow due to the reduction of the film thickness $f_{u}$. Comparing the experimental data on heat transfer to the films of liquids in the presence of shear stress on the film interface with the calculated ones $(7,11,13)$, we obtain the expression $f_{u}$ for in the region $W e \leq 250$

$$
f_{u}=S[1-0,1 \exp (-1,1086 \sqrt{W e})],
$$

where

$$
\begin{aligned}
& S=1,119-0,122 \sqrt{W e}+\left(0,07424+\frac{\operatorname{Re}}{9,153 \cdot 10^{6}}\right)(\sqrt{W e})^{2}-0,01808(\sqrt{W e})^{3}+ \\
& +1,775 \cdot 10^{-3}(\sqrt{W e})^{4}-7,8 \cdot 10^{-5}(\sqrt{W e})^{5}+1,28 \cdot 10^{-6}(\sqrt{W e})^{6},
\end{aligned}
$$

$W e=\frac{\rho_{2} u_{2}^{2} d_{o}}{\sigma}-$ the Weber number; $u_{2}-$ steam core velocity; $\rho_{2}-$ density of steam; $\sigma-$ surface tension.

Graphic interpretation (16) is shown in Figures 6,7.

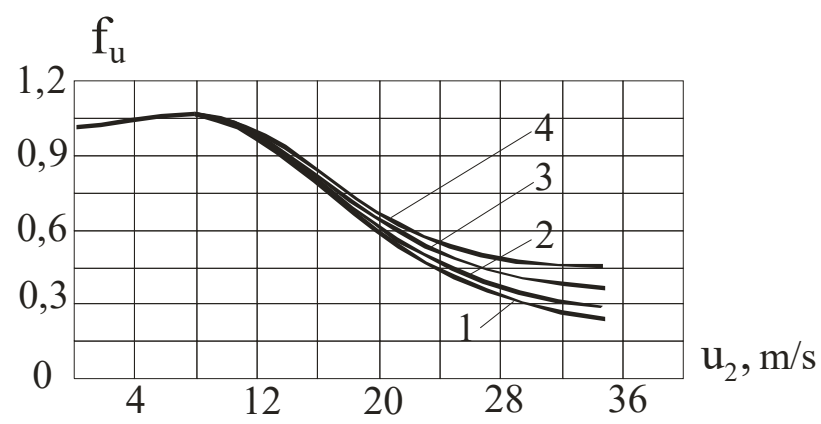

Figure 6. Dependence $f_{u}=f\left(u_{2}\right)$ on atmospheric pressure: $1-R e=1000,2-3000,3-6000,4-9000$.

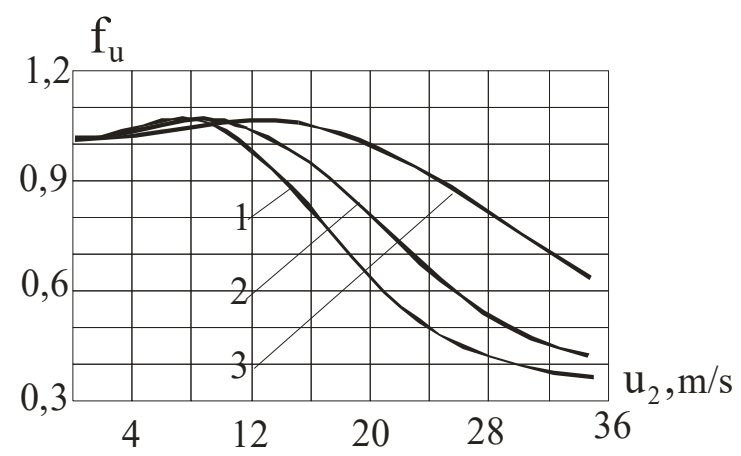

Figure 7. Dependence $f_{u}=f\left(u_{2}\right)$ at $\boldsymbol{R} \boldsymbol{e}=\mathbf{6 0 0 0}$ in the region of rarefaction:

$$
1-\rho_{2}=0,6 \mathrm{~kg} / \mathrm{m}^{3} ; 2-0,4 ; 3-0,2 \text {. }
$$


The nature of the curves in Figure 7 is due to the weakening of the dynamic action of the flow core on the film in the vacuum region, where the vapor density decreases, and hence the action of the flow core on the film, and, accordingly, on the turbulence parameters in it.

Finally, the algebraic function of the distribution of turbulent viscosity in flowing films with a concomitant steam flow in the range $W e \leq 250, G_{v} \leq 0,610^{-3} \mathrm{~m}^{2} / \mathrm{s}$ for pipes with diameters from 20 to $32 \mathrm{~mm}$ (investigated range) takes the form

$$
\frac{v_{t}}{v}=5 \cdot 10^{-5} \operatorname{Re}^{1,4}\left\{1+3,6\left[1-\exp \left(1-\frac{d}{d_{o}}\right)\right]\right\} f_{u} \eta^{2}\left(1-\eta^{2}\right)
$$

Graphical interpretation (17) for different phase costs is shown in Figure 8.

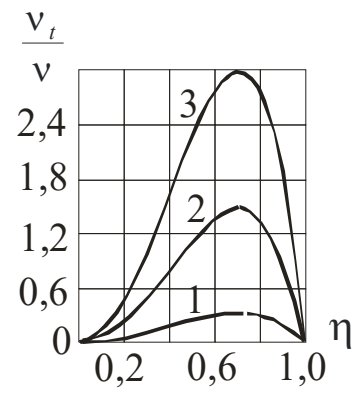

a

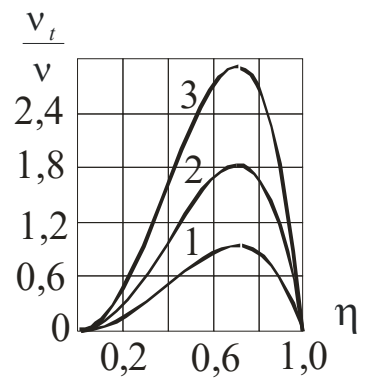

b

Figure 8. Dependence $\frac{v_{t}}{v}=f(\eta)$ on the ratio (17) for water at $t=100{ }^{\circ} \mathrm{C}, \boldsymbol{d}=\mathbf{0 , 0 2} \mathrm{m}$.

$$
\begin{gathered}
\mathbf{a}-u_{2}=10 \mathrm{~m} / \mathrm{s}, 1-\operatorname{Re}=1356 ; 2-4068 ; 3-6780 . \\
b-\operatorname{Re}=6780,1-u_{2}=35 \mathrm{~m} / \mathrm{s} ; 2-20 ; 3-0 .
\end{gathered}
$$

The coefficient of hydraulic friction of steam on the surface of the film $\xi$, which is included in the ratio for the shear stress on the film interface $\tau_{i}=\xi \rho_{2} \frac{u_{2}^{2}}{8}$, is calculated by the ratio

$$
\xi=\xi_{1}+\frac{627\left(d_{13} / d\right)}{F r_{2}^{1,26}\left\{\exp \left[\frac{1}{1,25 \cdot 10^{-2} K_{\delta}^{1,5}\left(F r-H_{d}^{1,1} \sqrt{d / d_{13}}\right)}\right]-1\right\}},
$$

where $\xi_{1}=\xi_{c}+3 \cdot 10^{-3}+4 \cdot 10^{-2} K_{\delta}$ is the coefficient of hydraulic friction for the first zone the zone of the mode of weak interaction; $\xi_{c}=\frac{0,316}{\operatorname{Re}_{2}^{0,25}}-$ coefficient of hydraulic friction on a dry wall; $\quad K_{\delta}=\sqrt[6]{\frac{G_{v}^{3} v}{g^{2}}} \sqrt{\frac{g \rho}{\sigma}} ; \quad H_{d}=\sqrt{\frac{\rho \sigma}{g d^{2} \rho_{2}^{2}}} ; \quad F r_{2}=\frac{u_{2}^{2}}{g d}-$ the Froude number; 
$\operatorname{Re}_{2}=\frac{u_{2} d \rho_{2}}{\mu_{2}}-$ the Reynolds number for steam; $\mu_{2}-$ steam dynamic viscosity; $d_{13}=0,013 \mathrm{~m}$. The transition to a zone of strong phase interaction is carried out under the condition $F r_{2}-H_{d}^{1,1} \sqrt{d / d_{o}} \geq 0$.

A comparison of the results of calculating the heat transfer intensity in the presence of a concomitant steam flow with experimental data obtained in a pipe with a diameter of 20 $\mathrm{mm}$ for films of water and sugar solution at atmospheric pressure and vacuum of $0,84 \mathrm{bar}$ is shown in Figure 9.10

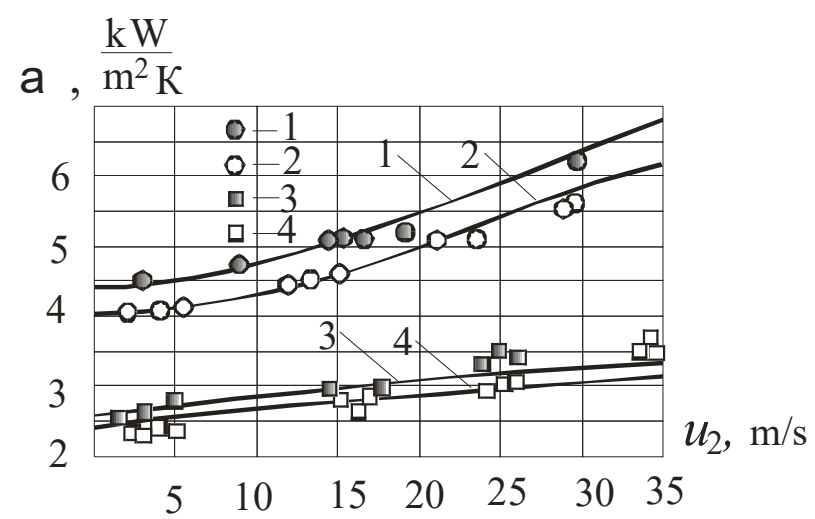

Figure 9. Dependence $\alpha=f\left(u_{2}\right)$ for water and sugar solutions for the pipe, $\boldsymbol{d}=\mathbf{2 0} \mathbf{m m}$.

1,2 - water, $t=100{ }^{\circ} \mathrm{C}, 1-G_{v}=0,510^{-3} \mathrm{~m}^{2} / \mathrm{s} ; 2-0,310^{-3} ; \operatorname{Pr}=1,79$.

3, 4 - sugar solution, $t=100{ }^{\circ} \mathrm{C}, D M=40 \% ; \operatorname{Pr}=5,58$.

Lines - calculation for $(7,11,17,18)$

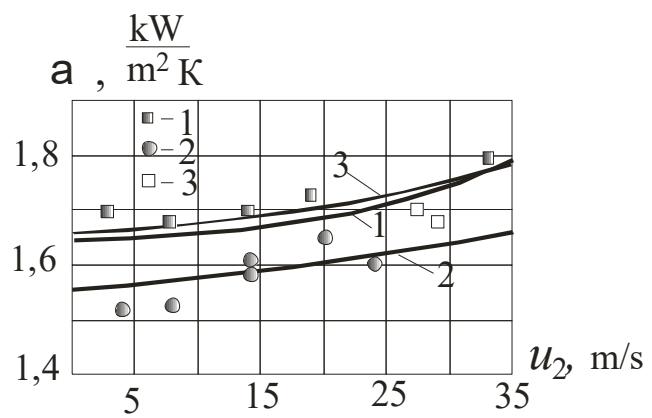

Figure 10. Dependence $\alpha=f\left(u_{2}\right)$ for sugar solution with a concentration of $40 \%$ in a pipe with a diameter of $d=20 \mathrm{~mm}$ in the vacuum of $0,86 \mathrm{bar}$.

$1-G_{v}=0,110^{-3} \mathrm{~m}^{2} / \mathrm{s} ; 2-0,310^{-3} ; 3-0,4510^{-3}$. The lines correspond to the calculation of $(7,11$,

$17,18)$ at the corresponding irrigation densities. 


\section{Modeling of heat transfer processes in films under bubble boiling conditions}

Equations $(7,11,17)$ reflect the process of heat transfer to the films flowing in the pipes in the mode of evaporation from the free surface in the absence of bubble boiling in the region of temperature differences that do not exceed the limit value

$$
\Delta t_{\text {min }}=\frac{2 \sigma T_{s a t}}{r_{f} \rho_{2} R_{m}}+\Delta_{f c},
$$

where $T_{\text {sat }}$ - saturation temperature, $K ; R_{m}$-roughness of the heat exchange surface (for new pipes $\left.R_{m}=0,5 \cdot 10^{-5} \mathrm{~m}\right), \Delta_{f c}$ - physicochemical temperature depression of the solution, $r_{f}-$ the heat of the phase transformation.

In the case $\Delta t \geq \Delta t_{\min }$ of the surface of heat exchange, depending on the nature of the distribution of microcracks, there are foci of bubble boiling, which leads to intensification of heat transfer in proportion to the increase in temperature pressure $\Delta t=t_{w}-t_{\text {sat }}$, which, by analogy with the conclusions of [15], is taken into account by (7) $K_{\text {boil }}$

$$
K_{\text {boil }}=1+0,4\left(\frac{\Delta t-\Delta t_{\min }}{\Delta t_{\min }}\right)^{1,2} \text {. }
$$

Then the ratio for calculating the intensity of heat transfer when it $\left(\Delta t-\Delta t_{\min } \geq 0\right)$ takes the form

$$
\alpha=\frac{\lambda}{\delta \sqrt{2}} \frac{(4+\varepsilon \operatorname{Pr})}{H N} K_{b o i l} .
$$

At $\left(\Delta t \leq \Delta t_{\text {min }}\right) K_{\text {boil }}=1$.

A comparison of the results of the calculation of heat transfer intensity in the presence of bubble boiling with experimental data in a pipe with a diameter of $20 \mathrm{~mm}$ for films of water and sugar solutions at atmospheric pressure at free flow and flow with concomitant steam flow is shown in Figures 11, 12
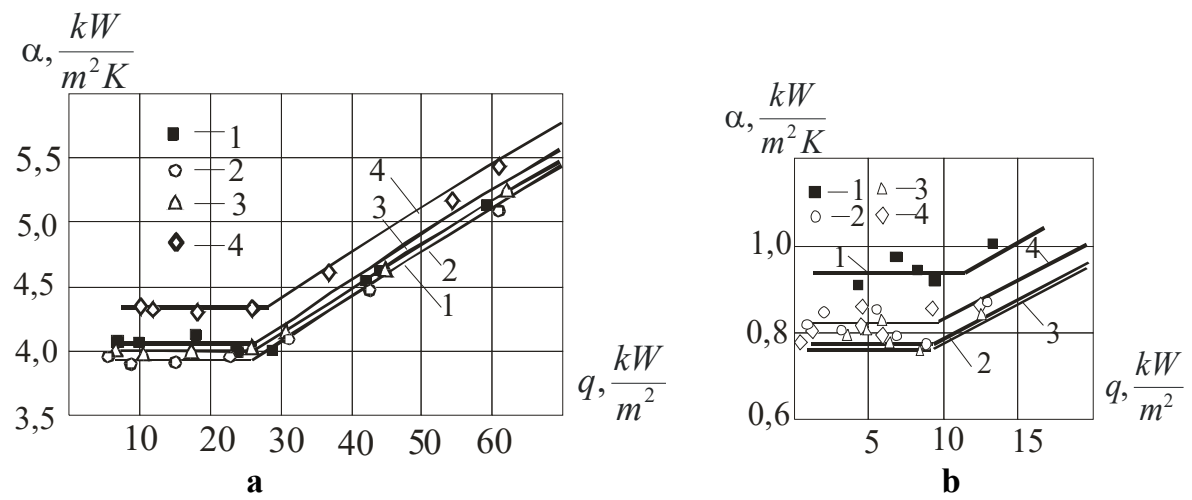

Figure 11. Dependence $\alpha=f(q)$ on free flow of films of water and sugar solutions,

$$
\left(t=100{ }^{\circ} \mathrm{C}, R_{c}=0,5 \cdot 10^{-5} \mathrm{~m}\right) \text {. }
$$

a - Water, $1-G_{v}=1 \cdot 10^{-4} \mathrm{~m}^{2} / \mathrm{s} ; 2-2 \cdot 10^{-4} ; 3-3 \cdot 10^{-4} ; 4-5,5 \cdot 10^{-4}$;

b - sugar solution, $D M=70 \%, 1-G_{v}=0,5 \cdot 10^{-4} \mathrm{~m}^{2} / \mathrm{s} ; 2-2 \cdot 10^{-4} ; 3-3 \cdot 10^{-4} ; 4-5,5 \cdot 10^{-4}$.

The lines correspond to the calculation of (20) at the appropriate irrigation densities. 


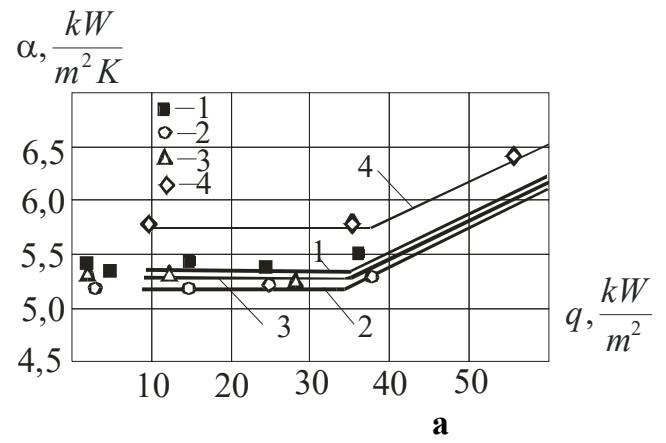

a

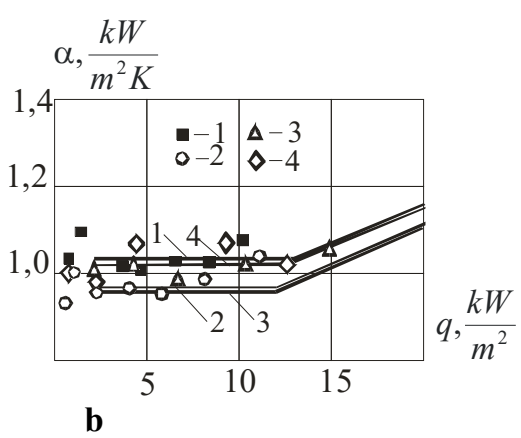

b

Figure 12. Dependence $\alpha=f(q)$ during the movement of steam with speed $u_{2}=25 \frac{\mathrm{m}}{\mathrm{s}}$.

$$
\begin{aligned}
& \left(t=100{ }^{\circ} \mathrm{C}, R_{c}=0,5 \cdot 10^{-5} \mathrm{~m}\right) . \\
& \text { a - Water, } 1-G_{v}=1 \cdot 10^{-4} \mathrm{~m}^{2} / \mathrm{s} ; 2-2 \cdot 10^{-4} ; 3-3 \cdot 10^{-4} ; 4-5,5 \cdot 10^{-4} \text {; }
\end{aligned}
$$

b - Sugar solution, $D M=70 \%, 1-G_{v}=1 \cdot 10^{-4} \mathrm{~m}^{2} / \mathrm{s} ; 2-2 \cdot 10^{-4} ; 3-3 \cdot 10^{-4} ; 4-5,5 \cdot 10^{-4}$.

The lines correspond to the calculation of (20) at the appropriate irrigation densities.

As can be seen from the graphs shown in Figures 11, 12, the transition to the boiling mode with increasing steam velocity is shifted to the region of larger heat fluxes. During the boiling of solutions, the temperature of the film is higher than the saturation temperature by the amount of physicochemical depression $\Delta_{f c}$, which is proportional to the mass concentration. Given the non-uniformity of the distribution of concentration over the film thickness and the lack of information about the concentration on the interfacial surface, the value $\Delta_{f c}$ is calculated from the average concentration. Therefore, the experimental heat transfer coefficients to the film solutions are defined as the ratio of heat flux to the temperature difference between the wall temperature and the average mass temperature of the film. In the case of free flow, the experimental average mass temperature of the film and the calculated coincide

But in the presence of steam flow over the film with increasing steam velocity, the film cools and its average mass temperature becomes less than the design. Therefore, the calculation of the heat flux to the boiling films of solutions in the presence of the vapor velocity above its surface must be performed taking into account the suppression of physicochemical temperature depression by the vapor flow, namely as

$$
q=\alpha\left(t_{w}-t_{s a t}-\Delta_{f c} f_{f c}\right)
$$

where $f_{f c}=\exp \left(-1,07 \cdot 10^{-2} \sqrt{W e} \sqrt[3]{P e}\right)-$ the function of suppression of physicochemical temperature depression by steam flow, $P e=\frac{4 G_{v}}{a_{m}}-$ the Peclet number, $a_{m}-$ temperature conductivity. 


\section{Conclusions}

1. An algebraic model of turbulent viscosity is proposed, which qualitatively reproduces the real distribution of turbulent viscosity over the entire thickness of the film flowing down the vertical surface.

2. Based on the proposed model, analytical expressions for temperature and velocity profiles in the film and the corresponding integral thermohydrodynamic characteristics for both free flow and motion with a concomitant flow of steam (gas) are obtained.

3. On the basis of the received decisions and the corresponding experimental data the analysis of influence of factors on intensity of heat transfer is executed and the generalizing equations for calculation of coefficients of heat transfer to films of solutions during evaporation are received.

\section{References}

1. Movchan V.T., Shkvar Ye.O., Kozlova T.V., (2012), Alhebro-dyferentsialni modeli koefitsiienta turbulentnoi viazkosti dlia prystinnykh techii, Avyatsyonno-kosmycheskaia tekhnyka y tekhnolohyia, 5(92), pp. 63-70.

2. Solodov V.G.(2011), Modelirovaniye turbulentnykh techeniy. Raschet bolshykh vikhrey, Kharkiv.

3. Shaleyev V.I. (2010), Primeneniye analiticheskikh metodov $v$ sovremennoy aeromekhanike. Chast 1. Teoriya pogranichnogo sloya, MFTI.

4. Kuzminov A.V., Lapin V.N., Chernyiy S.G. (2011), Metod rascheta turbulentnyih techeniy zhidkosti na osnove dvuhsloynoy k-e modeli, Vyichislitelnyie tehnologii, 6(5), pp. 73-86.

5. Peterson P.F., Schrock V.E., Kuhn S.Z. (1997), Recent experiments for laminar and turbulent film heat transfer in vertical tubes, Nucl.Eng. Des., 175, pp. 157-166.

6. Alhusseini A.A., Tuzla K., Chen K. (1998), Falling film evaporation of single component liquids, Int. J.Heat Mass Transfer, 41, pp. 1623-1623.

7. Alhusseini A.A., Chen J.C. (2000), Transport phenomena in turbulent falling films, Ind.Eng.Chem.Res., 39, pp. 2091-2100.

8. Asbik M., Ansari O., Zeghmati B. (2005), Numerical study of boundary layer transition in flowing film evaporation on horizontal elliptical cylinder, Heat Transfer, 48, pp. 645669.

9. Ye X., Yan W., Jiang Z., Li C. (2002), Hydrodynamics of free-falling wavy films and implications for enhanced heat transfer, Heat Transfer Eng, 23, pp. 48-60.

10. Nikhin Mascarehas, Issam Mudawar (2013), Investidation of eddy diffusivity and heat transfer coefficient for free-falling turulent liquid films subjected to sensible heating, Int.J.Heat and Mass Transfer, 64, pp. 647-660.

11. Forsiuk F.V., Bondar V.I., Vasylenko S.M., Shumylo K.O. (2009), Modeliuvannia turbulentnoho teploobminu v dvofaznykh paroridynnykh plivkovykh techiiakh, Naukovi pratsi NUKhT, 29, pp. 70-74.

12. Hloba O.V., Priadko O.V., Forsiuk O.V. (2009), Teploobmin u plivkakh yabluchnoho soku, Naukovi pratsi NUHT, 29, pp. 60-63.

13. Petrenko V., Zasyadko Ya. (2016), Heat transfer in down-flowing turbulent evaporating liquid films with developed wavy structure and co-current steam flow, Food and Environment safety, 15, pp. 284-298. 
14. Kostoglou M., Samaras K., Karapantsions T. (2010), Large wave characteristics and their downstream evoluyion at high Reynolds number falling films, AIChE, 56, pp. 11-23.

15. Gogonin I.I. (2010), Heat transfer in boiling of liquid in a film moving under gravity, Journal of Engineering Physics and Thermophysics, 83, pp. 876-881. 